\title{
Treatment Effect of Idebenone on Inspiratory Function in Patients With Duchenne Muscular Dystrophy
}

\author{
Gunnar M. Buyse, MD, PhD, ${ }^{1 *}$ Thomas Voit, MD, ${ }^{2}$ Ulrike Schara, MD, ${ }^{3}$ Chiara S.M. Straathof, MD, ${ }^{4}$ \\ Maria Grazia D'Angelo, MD, ${ }^{5}$ Günther Bernert, MD, ${ }^{6}$ Jean-Marie Cuisset, MD, ${ }^{7}$ Richard S. Finkel, MD, ${ }^{8}$ \\ Nathalie Goemans, MD, ${ }^{1}$ Christian Rummey, PhD, ${ }^{9}$ Mika Leinonen, Ms, ${ }^{9}$ Oscar H. Mayer, MD, ${ }^{10}$ \\ Paolo Spagnolo, MD, ${ }^{11}$ Thomas Meier, PhD, ${ }^{11}$ and Craig M. McDonald, MD, ${ }^{12}$ \\ for the DELOS Study Group ${ }^{1-9,11-20}$
}

This is an open access article under the terms of the Creative Commons Attribution-NonCommercial License, which permits use, distribution and reproduction in any medium, provided the original work is properly cited and is not used for commercial purposes.

${ }^{1}$ University Hospitals Leuven, Leuven, Belgium.

${ }^{2}$ Institut de Myologie, UPMC INSERM UMR 974, CNRS FRE 3617, Groupe Hospitalier de la Pitié Salpêtrière, Paris, France.

${ }^{3}$ Universitätsklinikum, Essen, Germany.

${ }^{4}$ LUMC, Leiden, the Netherlands.

${ }^{5}$ IRCCS Eugenio Medea, Lecco, Italy.

${ }^{6}$ G.v. Preyer'sches Kinderspital, Wien, Austria.

${ }^{7}$ CHRU de Lille, Lille, France.

${ }^{8}$ Nemours Children's Hospital, Orlando, Florida.

${ }^{9} 4$ Pharma, Liestal, Switzerland.

${ }^{10}$ Division of Pulmonology, Children's Hospital of Philadelphia, Philadelphia, Pennsylvania.

\footnotetext{
${ }^{11}$ Santhera Pharmaceuticals, Liestal, Switzerland.

${ }^{12}$ University of California Davis Medical Center, Sacramento, California.

${ }^{13}$ CHUV, Lausanne, Switzerland.

${ }^{14}$ Centro Clinico Nemo, Milano, Italy.

${ }^{15}$ Hospital Universitari i Politècnic La Fe de Valencia, Valencia, Spain.

${ }^{16}$ Astrid Lindgren Children's Hospital, Stockholm, Sweden.

${ }^{17}$ University of Texas Southwestern Medical Center, Dallas, Texas.

${ }^{18}$ Seattle Children's Hospital, Seattle, Washington.

${ }^{19}$ Universitäts-Klinikum Freiburg, Freiburg, Germany.

${ }^{20}$ Azienda Ospedaliera Universitaria della Seconda Università degli Studi di Napoli, Napoli, Italy.
}

The present address of Thomas Voit is UCL Institute of Child Health, Great Ormond Street Hospital, London, United Kingdom.

DELOS Study Group (sorted by country): Austria: G. Bernert, F. Knipp (Vienna). Belgium: G.M. Buyse, N. Goemans, M. Van den Hauwe (Leuven). France: T. Voit, V. Doppler, T. Gidaro (Paris); J.-M. Cuisset, S. Coopman (Lille). Germany: U. Schara, S. Lutz (Essen); J. Kirschner, S. Borell, M. Will (Freiburg). Italy: M.G. D'Angelo, E. Brighina, S. Gandossini (Lecco); K. Gorni, E. Falcier (Milan); L. Politano, P. D'Ambrosio, A. Taglia (Naples); The Netherlands: J.J.G.M. Verschuuren, C.S.M. Straathof (Leiden). Spain: J.J. Vílchez Padilla, N. Muelas Gómez (Valencia) Sweden: T. Sejersen, M. Hovmöller (Stockholm). Switzerland: P.-Y. Jeannet, C. Bloetzer (Lausanne). USA: S. Iannaccone, D. Castro (Dallas); G. Tennekoon, R. Finkel, C. Bönnemann (Philadelphia); C. McDonald, E. Henricson, N. Joyce (Sacramento); S. Apkon, R.C. Richardson (Seattle).

Conflicts of interest: GMB was investigator for clinical trials in DMD sponsored by Santhera Pharmaceuticals, Prosensa Therapeutics BV and GlaxoSmithKline (GSK). TV was investigator for DMD clinical trials sponsored by PTC Therapeutics, GSK, Prosensa, and Santhera Pharmaceuticals; he serves as a scientific advisory board member to Prosensa. US was investigator for DMD clinical trials sponsored by PTC, LillyPharma, Santhera Pharmaceuticals, Prosensa, and GSK. CSMS has participated in DMD trials sponsored by GSK, Prosensa, and Santhera Pharmaceuticals. RSF has participated in DMD studies sponsored by PTC, the NIH (UDP R01NS043264, Wellstone 5U54AR052646-03, Imaging DMD R01AR056973, and FOR-DMD U01 NS061799-01A2), Lilly, MDA, Sarepta; and served as DSMB member for the Sarepta 201 study, advisor to Catabasis. CMM has served as a consultant for DMD trials unrelated to this scope of work for PTC, Prosensa, Sarepta, Eli Lilly, Pfizer, Halo Therapeutics, Cardero, and Mitokyne, and serves on External Advisory Boards related to DMD for PTC and Eli Lilly. OHM is consultant for Genentech/Roche, FibroGen, and Santhera. MGD, GB, J-MC, and NG have declared that no competing interests exist. TM is a regular employee of Santhera Pharmaceuticals. GMB and TM are co-inventors of relevant patent applications. The investigators and authors had sole discretion over study design, collection, analysis, and interpretation of data, writing of the report, and decision to submit it for publication. GMB is senior clinical investigator of the Research Foundation-Flanders (FWO Vlaanderen, Belgium).

${ }^{*}$ Correspondence to: Gunnar Buyse, MD, PhD, University Hospitals Leuven, Herestraat 49, B-3000 Leuven, Belgium. E-mail: gunnar.buyse@uzleuven.be

Received 4 February 2016; Revised 15 June 2016; Accepted 25 July 2016.

DOI 10.1002/ppul.23547

Published online 29 August 2016 in Wiley Online Library

(wileyonlinelibrary.com).

(c) 2016 The Authors. Pediatric Pulmonology Published by Wiley Periodicals, Inc. 


\begin{abstract}
Summary. Assessment of dynamic inspiratory function may provide valuable information about the degree and progression of pulmonary involvement in patients with Duchenne muscular dystrophy (DMD). The aims of this study were to characterize inspiratory function and to assess the efficacy of idebenone on this pulmonary function outcome in a large and well-characterized cohort of 10-18 year-old DMD patients not taking glucocorticoid steroids (GCs) enrolled in the phase 3 randomized controlled DELOS trial. We evaluated the effect of idebenone on the highest flow generated during an inspiratory FVC maneuver (maximum inspiratory flow; V'I, $\max (\mathrm{FVC})$ ) and the ratio between the largest inspiratory flow during tidal breathing (tidal inspiratory flow; V'I, $\max (\mathrm{t})$ ) and the V'I, $\max (\mathrm{FVC})$. The fraction of the maximum flow that is not used during tidal breathing has been termed inspiratory flow reserve (IFR). DMD patients in both treatment groups of DELOS (idebenone, $n=31$; placebo: $n=33$ ) had comparable and abnormally low V'I, $\max (F V C)$ at baseline. During the study period, V'I, $\max (F V C)$ further declined by $-0.29 \mathrm{~L} / \mathrm{sec}$ in patients on placebo $(95 \% \mathrm{Cl}:-0.51,-0.08 ; P=0.008$ at week 52$)$, whereas it remained stable in patients on idebenone (change from baseline to week 52 : $0.01 \mathrm{~L} / \mathrm{sec} ; 95 \% \mathrm{Cl}:-0.22,0.24$; $P=0.950)$. The between-group difference favoring idebenone was $0.27 \mathrm{~L} / \sec (P=0.043)$ at week 26 and $0.30 \mathrm{~L} / \mathrm{sec}(P=0.061)$ at week 52 . In addition, during the study period, IFR improved by $2.8 \%$ in patients receiving idebenone and worsened by $-3.0 \%$ among patients on placebo (between-group difference $5.8 \%$ at week $52 ; P=0.040$ ). Although the clinical interpretation of these data is currently limited due to the scarcity of routine clinical practice experience with dynamic inspiratory function outcomes in DMD, these findings from a randomized controlled study nevertheless suggest that idebenone preserved inspiratory muscle function as assessed by V'I, max(FVC) and IFR in patients with DMD. Pediatr Pulmonol. 2017;52:508-515.

(c) 2016 The Authors. Pediatric Pulmonology Published by Wiley Periodicals, Inc.
\end{abstract}

Key words: Duchenne muscular dystrophy; idebenone; respiratory function; inspiratory flow.

Funding source: Santhera Pharmaceuticals.

\section{INTRODUCTION}

Duchenne muscular dystrophy (DMD), the most common and severe neuromuscular disorder of childhood,

\begin{tabular}{|c|c|}
\hline \multicolumn{2}{|l|}{ ABBREVIATIONS } \\
\hline $\mathrm{CI}$ & confidence interval \\
\hline DMD & Duchenne muscular dystrophy \\
\hline FEV1 & $\begin{array}{l}\text { forced expiratory volume in } \\
1 \mathrm{sec}\end{array}$ \\
\hline FVC & forced vital capacity \\
\hline GC & glucocorticoid steroids \\
\hline IFR & inspiratory flow reserve \\
\hline PEF & peak expiratory flow \\
\hline MEP & $\begin{array}{l}\text { maximum static expiratory } \\
\text { pressure }\end{array}$ \\
\hline MIP & $\begin{array}{l}\text { maximum static inspiratory } \\
\text { pressure }\end{array}$ \\
\hline MMRM & $\begin{array}{l}\text { mixed model for repeated } \\
\text { measurements }\end{array}$ \\
\hline SD & standard deviation \\
\hline V'I,max(FVC) [L/sec] & $\begin{array}{l}\text { largest inspiratory flow during } \\
\text { an inspiratory FVC maneuver }\end{array}$ \\
\hline $\mathrm{V}^{\prime} \mathrm{I}, \max (\mathrm{t})[\mathrm{L} / \mathrm{sec}]$ & $\begin{array}{l}\text { largest inspiratory flow during } \\
\text { tidal breathing }\end{array}$ \\
\hline V'I,max(t)/V'I,max(FVC) & inspiratory flow ratio \\
\hline $1-\left(\mathrm{V}^{\prime} \mathrm{I}, \max (\mathrm{t}) / \mathrm{V}^{\prime} \mathrm{I}, \max (\mathrm{FVC})\right)[\%]$ & $\begin{array}{l}\text { inspiratory flow reserve (IFR } \\
\text { in \%) }\end{array}$ \\
\hline $\mathrm{V}^{\prime} \mathrm{I}, \max (\mathrm{FVC})-\mathrm{V}^{\prime} \mathrm{I}, \max (\mathrm{t})[\mathrm{L} / \mathrm{sec}]$ & $\begin{array}{l}\text { inspiratory flow reserve (IFR } \\
\text { in } \mathrm{L} / \mathrm{sec} \text { ) }\end{array}$ \\
\hline
\end{tabular}

is an inexorably progressive and ultimately fatal X-linked disease, characterized by muscle degeneration and atrophy. ${ }^{1}$ DMD patients generally lose ambulation before the age of 12 and develop respiratory or cardiac complications in their late teenage years. Routine use of glucocorticoid steroids (GCs) and the introduction of mechanical insufflation-exsufflation devices to improve airway clearance and non-invasive ventilation to prevent hypoventilation have become standard of care which together have increased survival in DMD to late in the second and frequently well into the third decade. ${ }^{2-5}$ Indeed, progressive respiratory muscle weakness leads to restrictive respiratory disease, hypoventilation, ineffective cough, recurrent pulmonary infections, atelectasis, and respiratory failure. $^{6-8}$ Accordingly, serial measurement of lung function is an important part of the standard of care of patients with DMD. ${ }^{9}$

Respiratory function and respiratory muscle strength in patients with DMD can be assessed by measuring lung volumes ${ }^{10}$ (e.g., forced vital capacity [FVC] and forced expiratory volume in one second [FEV1]) and flows (peak expiratory flow [PEF]) as well as inspiratory and expiratory static airway pressures (e.g., maximal inspiratory pressure [MIP] and maximal expiratory pressure [MEP]). Since a FVC maneuver requires both maximal inspiration and exhalation, and PEF requires maximal expiratory muscle function, loss of this muscle function will produce a decline in both FVC and PEF. ${ }^{11-15}$ Yet, 
these maneuvers require maximal effort and cooperation, and can be challenging to perform in young patients and patients with cognitive disability.

In DMD patients, diaphragm and inspiratory muscle function are progressively impaired. Therefore, assessing dynamic inspiratory muscle function may also provide additional information on the status and progression of pulmonary involvement in patients with DMD. ${ }^{16}$ Indeed, the largest flow generated during an inspiratory FVC maneuver (maximum inspiratory flow; $\mathrm{V}^{\prime} \mathrm{I}, \max (\mathrm{FVC})$ ) is abnormally reduced and the ratio between the largest inspiratory flow during tidal breathing (tidal inspiratory flow; V'I,max $(\mathrm{t}))$ and the V'I,max(FVC) is increased and the resulting inspiratory flow reserve (IFR) ${ }^{16}$ consequently decreased.

In a recent Phase 3 randomized, placebo-controlled clinical trial (DELOS; ClinicalTrials.gov number: NCT01027884) in patients with DMD not using concomitant GCs, idebenone, a short-chain benzoquinone, has been shown to reduce the loss of respiratory function as assessed by PEF, FVC, and FEV1 over the 52-week study period. ${ }^{17}$ The aims of the present analysis were to characterize dynamic inspiratory muscle function in the largest cohort of DMD patients analyzed thus far for this parameter, and to assess the efficacy of idebenone compared to placebo on this inspiratory function outcome in the DELOS population.

\section{PATIENTS AND METHODS}

The study population consisted of 64 patients aged 10-18 years (mean age, 14.3 years) with a documented diagnosis of DMD. Subjects were enrolled in DELOS, a multi-center, phase 3 clinical trial comparing the efficacy of $900 \mathrm{mg} /$ day idebenone (Raxone ${ }^{\mathbb{R}}$ provided by Santhera Pharmaceuticals, Liestal, Switzerland) compared to placebo. ${ }^{17}$ Patients were eligible if they had a PEF percent predicted (PEF\%p) $<80 \%$ at baseline and had stopped taking GC at least 12 months prior to enrollment. In addition, patients were not allowed to take GC during the 52-week study period. Standard spirometry was performed at hospital visits at baseline and at weeks 13, 26, 39, and 52 using a Pneumotrac Spirometer 6800 (Vitalograph, Buckingham, UK) with the aid of a qualified, trained, and certified operator and in accordance with the American Thoracic Society/ European Respiratory Society guidelines. ${ }^{18}$ For PEF, $\mathrm{FVC}$, and $\mathrm{FEV}_{1}$, the largest available test result from a minimum of three and up to five consecutive maneuvers was used. Since lung volume and associated pulmonary function is influenced by height, race, and age, these measures are presented relative to normative data as percent of predicted, which allows for longitudinal comparison. ${ }^{17-20}$ Similarly, for MIP and MEP, the highest value from a minimum of three and up to five consecutive maneuvers was used and normalized using established equations. ${ }^{21}$ Patient height was derived from ulnar length measures. ${ }^{22,23}$

In order to evaluate inspiratory function, patients were asked to breathe normally and perform several tidal breaths into the spirometer. At the end of the inspiratory tidal breathing, the patient was asked to perform a maximal exhalation followed by a maximal inspiratory maneuver to total lung capacity (Fig. 1). Patients performed between three and five consecutive inspiratory function maneuvers at each study visit following the PEF and FVC function tests. Sufficient time was allowed for patients to rest between pulmonary function tests as well as between individual maneuvers to minimize fatigue. All available data obtained from inspiratory function tests were recorded and stored without assessment of acceptability, as at this time no acceptance criteria for this maneuver are available. From any individual inspiratory function maneuver, the maximum inspiratory flow during tidal breathing (V'I, $\max (\mathrm{t}))$ and the maximum inspiratory flow during an inspiratory FVC maneuver (V'I,max (FVC)) was recorded as described by De Bruin et al. ${ }^{16}$ (Fig. 1). To limit the influence of both spuriously low and high tidal flow values without requiring a manual assessment of the quality of the tidal breathing, the lowest of the available V'I,max(t) recorded during a set of consecutive tests was used to calculate the inspiratory flow ratio as the ratio between the $\mathrm{V}^{\prime} \mathrm{I}, \max (\mathrm{t})$ determined as described above and the highest V'I,max(FVC) available from the set of consecutive maneuvers. In addition,

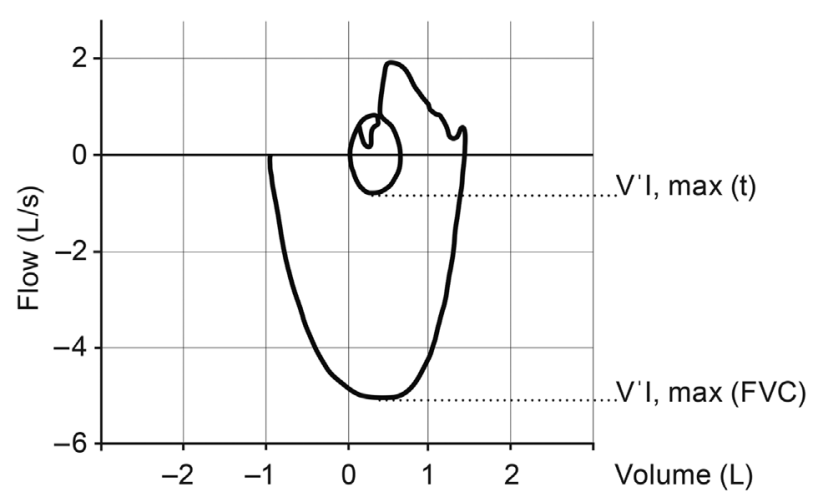

Fig. 1. Assessment of inspiratory function. Inspiratory flowvolume curve. The subject breathes tidally until a repeatable inspiratory tidal flow-volume curve is obtained; he then expires to residual volume and makes a maximum inspiratory effort to total lung capacity. The largest value during tidal breathing (V'I,max(t)) and the largest value of inspiratory flow during the maximum effort maneuver (V'I,max(FVC)) are determined. The inspiratory flow ratio is calculated as V'I,max(t)/V'l,max(FVC) and the IFR is calculated as $1-\left(V^{\prime}, \max (t) / V^{\prime} l, \max (F V C)\right)$ and expressed as percentage. In addition, the difference V'I, $\max (F V C)$ - V'I, $\max (\mathrm{t})$ is expressed as IFR in L/sec. 
the inspiratory flow reserve (IFR), a pre-specified tertiary endpoint of the DELOS trial, was calculated as $1-\left(\mathrm{V}^{\prime} \mathrm{I}, \max (\mathrm{t}) / \mathrm{V}^{\prime} \mathrm{I}, \max (\mathrm{FVC})\right)$ and expressed as percentage. According to data from De Bruin et al., ${ }^{16}$ the inspiratory flow ratio is increased and consequently the IFR is reduced in patients with DMD compared to healthy subjects (i.e., a lower IFR value indicates more severe functional impairment). As a sensitivity analysis, IFR values were also calculated using both V'I,max(t) and V'I,max(FVC) from the same individual maneuver, and the highest (i.e., best) IFR expressed as percentage was selected for comparison. The reserve in flow was also analyzed as IFR and expressed in L/sec, determined as the difference $\mathrm{V}^{\prime} \mathrm{I}, \max (\mathrm{FVC})-\mathrm{V}^{\prime} \mathrm{I}, \max (\mathrm{t})$.

Change from baseline and differences in treatment groups was analyzed using a mixed model for repeated measures (MMRM) using SAS $9.3,{ }^{24}$ as described previously. ${ }^{17}$ For comparisons between treatment groups, all available data from all post-baseline visits were used as response variables in the model. Treatment group, visit, and the interaction between the treatment group and visit were used as fixed factors in the model and the baseline assessment as a covariate. Withinsubject coefficients of variation and correlations between parameters (Spearman's rho) were calculated using R. ${ }^{25}$

\section{RESULTS}

Patient demographics of the DELOS trial have been previously reported ${ }^{17}$ and are briefly summarized in Table 1. At baseline, patients $(\mathrm{N}=64)$ had an average age of 14.3 years (SD: 2.7, range: 10.1-19.0), 59 (92.2\%) were non-ambulatory and 28 (43.8\%) had never used GC.
TABLE 1-Patient Characteristics of the DELOS Trial Population

\begin{tabular}{lccc}
\hline & $\begin{array}{c}\text { Idebenone } \\
(\mathrm{N}=31)\end{array}$ & $\begin{array}{c}\text { Placebo } \\
(\mathrm{N}=33)\end{array}$ & $\begin{array}{c}\text { Total } \\
(\mathrm{N}=64)\end{array}$ \\
\hline Age (years) & $13.5(2.7)$ & $15.0(2.5)$ & $14.3(2.7)$ \\
$\begin{array}{l}\text { Non-ambulatory (\%) } \\
\text { Prior glucocorticoid use }\end{array}$ & $28(90.3)$ & $31(93.9)$ & $59(92.2)$ \\
$\quad$ Yes (\%) & $17(54.8)$ & $19(57.6)$ & $36(56.3)$ \\
$\quad$ No (\%) & $14(45.2)$ & $14(42.4)$ & $28(43.8)$ \\
PEF \%p strata & & & \\
$\quad$ PEF <40\% & $5(16.1)$ & $7(21.2)$ & $12(18.8)$ \\
PEF 40-80\% & $26(83.9)$ & $26(78.8)$ & $52(81.3)$ \\
\hline
\end{tabular}

Previous GC users had stopped taking GCs at least 12 months prior to enrollment (mean: 3.7 years, SD: 2.1 years, range: $0.9-8.9$ years). ${ }^{17}$ The baseline characteristics of pulmonary function parameters are shown in Table 2; there were no statistically significant differences between treatment groups for any of the expiratory and inspiratory function tests and for maximum static airway pressures.

As previously described in the original report of this study, ${ }^{17}$ treatment effects for idebenone were observed for the change in PEF, FEV1, and FVC (reported as percent predicted or non-normalized values). Specifically, between-group differences for PEF\%p, PEF, FVC, FEV1\%p, and FEV1 for the change from baseline to week 52 were statistically significant and betweengroup differences for $\mathrm{FVC} \% \mathrm{p}$ reached a strong trend $(P<0.05$ at weeks 13,26 , and $39 ; P=0.082$ at week 52). ${ }^{17}$ Overall, the results of the study indicate a

TABLE 2-Baseline Pulmonary Function of the DELOS Trial Population

\begin{tabular}{|c|c|c|c|c|}
\hline & Idebenone $(\mathrm{N}=31)$ & Placebo $(\mathrm{N}=33)$ & Between-group comparison $P$-value* & Total $(\mathrm{N}=64)$ \\
\hline \multicolumn{5}{|l|}{ Expiratory function } \\
\hline $\mathrm{PEF}(\mathrm{L} / \mathrm{min})$ & $217.7(48.6)$ & $233.8(59.6)$ & 0.241 & $226.0(54.7)$ \\
\hline $\mathrm{PEF} \% \mathrm{p}$ & $53.5(10.3)$ & $54.2(13.2)$ & 0.811 & $53.8(11.8)$ \\
\hline FVC (L) & $1.88(0.47)$ & $1.86(0.50)$ & 0.879 & $1.87(0.48)$ \\
\hline $\mathrm{FVC} \% \mathrm{p}$ & $55.3(15.8)$ & $50.4(20.0)$ & 0.277 & $52.8(18.1)$ \\
\hline FEV1 (L) & $1.57(0.38)$ & $1.60(0.54)$ & 0.805 & $1.58(0.47)$ \\
\hline FEV1\%p & $53.6(16.1)$ & $49.5(20.6)$ & 0.375 & $51.4(18.5)$ \\
\hline \multicolumn{5}{|l|}{ Inspiratory function } \\
\hline V'I, $\max (\mathrm{t})(\mathrm{L} / \mathrm{sec})$ & $0.73(0.22)$ & $0.80(0.46)$ & 0.456 & $0.76(0.36)$ \\
\hline $\mathrm{V}^{\prime} \mathrm{I}, \max (\mathrm{FVC})(\mathrm{L} / \mathrm{sec})$ & $2.77(0.88)$ & $2.82(0.87)$ & 0.838 & $2.79(0.87)$ \\
\hline Inspiratory flow ratio & $28.7(12.3)$ & $29.8(15.0)$ & 0.750 & $29.3(13.7)$ \\
\hline $\operatorname{IFR}(\%)$ & $71.3(12.3)$ & $70.2(15.0)$ & 0.750 & $70.8(13.7)$ \\
\hline IFR (L/sec) & $2.04(0.89)$ & $2.01(0.91)$ & 0.921 & $2.03(0.89)$ \\
\hline \multicolumn{5}{|c|}{ Maximum static airway pressure } \\
\hline $\operatorname{MIP}\left(\mathrm{cmH}_{2} \mathrm{O}\right)$ & $47.3(24.4)$ & $44.6(16.9)$ & 0.609 & $45.9(20.8)$ \\
\hline $\mathrm{MIP} \% \mathrm{p}$ & $43.5(22.2)$ & $38.5(16.9)$ & 0.318 & $41.0(19.6)$ \\
\hline $\mathrm{MEP}\left(\mathrm{cmH}_{2} \mathrm{O}\right)$ & $40.6(15.6)$ & $39.7(16.6)$ & 0.827 & $40.1(16.0)$ \\
\hline $\mathrm{MEP} \% \mathrm{p}$ & $28.3(12.2)$ & $25.1(12.2)$ & 0.307 & $26.6(12.2)$ \\
\hline
\end{tabular}

Data are mean (SD) or number (\%). IFR, inspiratory flow reserve.

${ }^{*}$ By $t$-test. 
TABLE 3-Correlation of Inspiratory and Expiratory Respiratory Function Parameters and Static Mouth Pressures

\begin{tabular}{lccc}
\hline Spearman's rho (r) & $\begin{array}{c}\text { V'I,max(FVC) } \\
(\mathrm{L} / \mathrm{sec})\end{array}$ & $\begin{array}{c}\text { IFR } \\
(\%)\end{array}$ & $\begin{array}{c}\text { IFR } \\
(\mathrm{L} / \mathrm{sec})\end{array}$ \\
\hline Inspiratory flow ratio & -0.45 & -1.00 & -0.77 \\
IFR (\%) & 0.45 & - & 0.77 \\
IFR (L/sec) & 0.89 & 0.77 & - \\
V'I,max(FVC) (L/sec) & - & 0.45 & 0.89 \\
V'I, max (t) (L/sec) & 0.11 & -0.79 & -0.28 \\
PEF (L/min) & 0.63 & 0.37 & 0.60 \\
FVC (L) & 0.47 & 0.08 & 0.35 \\
FEV1 (L) & 0.51 & 0.19 & 0.42 \\
MEP (cm $\left.\mathrm{H}_{2} \mathrm{O}\right)$ & 0.26 & 0.01 & 0.18 \\
MIP (cm $\left.\mathrm{H}_{2} \mathrm{O}\right)$ & -0.40 & -0.18 & -0.36 \\
\hline
\end{tabular}

consistent slowing of the decline of these pulmonary function outcomes. On the other hand, no statistically significant differences between idebenone and placebo groups were seen for changes in MIP and MEP. The lack of effect for the outcome in MIP and MEP could be explained by severe disability at baseline (Table 2) and early appearance of floor effects. Historically, decline in MIP and MEP have been shown to be among the first signs of respiratory dysfunction in DMD. ${ }^{15}$ Baseline data from this study are consistent with data reported from a large natural history study demonstrating severely reduced values of MIP and MEP at very young ages. ${ }^{26-28}$ Furthermore, in patients $10-18$ years of age as included in the DELOS study, MIP and MEP do not consistently decline ${ }^{28}$ which could have influenced the outcomes for these parameters.

\section{Characterization of V'I, $\max (\mathrm{FVC})$ in DMD Patients}

Patients enrolled in the DELOS trial had abnormal V'I,max (FVC) at baseline (2.79 L/sec, SD: 0.87; Table 2) consistent with the data reported by De Bruin et al. ${ }^{16}$ V'I,max (FVC) correlated well with PEF $(r=0.63)$, FEV1 $(r=0.51)$, and FVC $(r=0.47)$ (Table 3$)$, and was reliably performed by all patients. On the other hand, $\mathrm{V}^{\prime} \mathrm{I}, \max (\mathrm{FVC})$ correlated weakly with MEP $(\mathrm{r}=0.26)$.

Additional analysis revealed that V'I,max(FVC) was similar irrespective of GC use and ambulatory status at baseline (Table 4). On the other hand, as expected, older patients (above 14 years, median age of the study) had larger V'I, $\max (\mathrm{FVC})$ compared to the younger patient subgroup (below 14 years), probably due to body growth. As the V'I,max $(\mathrm{t})$ did not differ between age groups, this resulted in higher (e.g., better preserved) IFR in older patients compared to younger patients.

\section{Longitudinal Change in V'I, $\max (F V C)$ and IFR and Effect of Idebenone}

During the study period, V'I, $\max (\mathrm{FVC})$ continued to decline in patients on placebo, with a change from baseline to week 52 of $-0.29 \mathrm{~L} / \mathrm{sec}$ (95\%CI: $-0.51,-0.08$; $P=0.008)$. Conversely, among patients in the idebenone group, the V'I, $\max (\mathrm{FVC})$ remained stable throughout the study period with a change from baseline to week 52 of $0.01 \mathrm{~L} / \mathrm{sec}(95 \% \mathrm{CI}:-0.22,0.24 ; P=0.950)$, resulting in a between-group difference of $0.30 \mathrm{~L} / \mathrm{sec}(95 \% \mathrm{CI}:-0.01$, 0.62; $P=0.061$ ) (Fig. 2).

Likewise, during the study period, IFR increased by $2.8 \%$ (indicating improvement; 95\%CI: $-1.3,6.8$; $P=0.174$ ) among patients receiving idebenone and decreased by $-3.0 \%$ (indicating worsening; 95\%CI: $-6.8,0.7 ; P=0.114$ ) among patients on placebo with a significant between-group difference at 52 weeks of 5.78\% (95\%CI: $0.28,11.27 ; P=0.040$ ) (Fig. 3).

Similar results were obtained when the best IFR was calculated from V'I,max $(t)$ paired with V'I,max(FVC), both obtained from one individual maneuver. For this sensitivity analysis, the change from baseline to week 52 was $3.3 \%$ (95\%CI: $-1.2,7.8 ; P=0.149)$ for the idebenone group compared to $-1.7 \%$ (95\% CI: $-5.9,2.5 ; P=0.430)$ for the placebo group. The between-group difference for the change from baseline to week 52 was $5.0 \%$ (95\% CI: -1.2 , $11.2 ; P=0.113$ ) in favor of idebenone treatment.

In an alternative analysis, IFR was calculated as the difference between V'I,max (FVC) and V'I,max $(\mathrm{t})$ and expressed in L/sec. Here, the idebenone-treated patients also remained stable compared to a steady decline, indicating worsening, seen in patients in the placebo group (Fig. 4). The between-group difference was statistically significant from week 26 onwards and reached a difference of $0.35 \mathrm{~L} / \mathrm{sec}$ at week $52(95 \% \mathrm{CI}$ : $0.07,0.63 ; P=0.016$ ).

TABLE 4-Baseline Inspiratory Function Stratified by GC Use, Median Age, and Ambulatory Status

\begin{tabular}{|c|c|c|c|c|c|}
\hline & Patients (n) & V'I,max(FVC) (L/sec) & $\mathrm{V}^{\prime} \mathrm{I}, \max (\mathrm{t})(\mathrm{L} / \mathrm{sec})$ & IFR $(\%)$ & IFR (L/sec) \\
\hline All patients & 64 & $2.79(0.87)$ & $0.76(0.36)$ & $70.7(13.7)$ & $2.03(0.89)$ \\
\hline GC-näve patients & 28 & $2.83(0.93)$ & $0.66(0.30)$ & $74.9(12.0)$ & $2.17(0.92)$ \\
\hline Previous GC users & 36 & $2.76(0.82)$ & $0.85(0.39)$ & $67.5(14.2)$ & $1.92(0.87)$ \\
\hline Age $\geq 14$ years & 32 & $3.07(0.94)$ & $0.73(0.37)$ & $74.6(12.4)$ & $2.34(0.97)$ \\
\hline Age $<14$ years & 32 & $2.52(0.70)$ & $0.80(0.36)$ & $66.9(14.0)$ & $1.72(0.68)$ \\
\hline Non-ambulatory patients only & 59 & $2.82(0.84)$ & $0.76(0.36)$ & $71.1(13.7)$ & $2.06(0.89)$ \\
\hline
\end{tabular}

Data are mean (SD). 


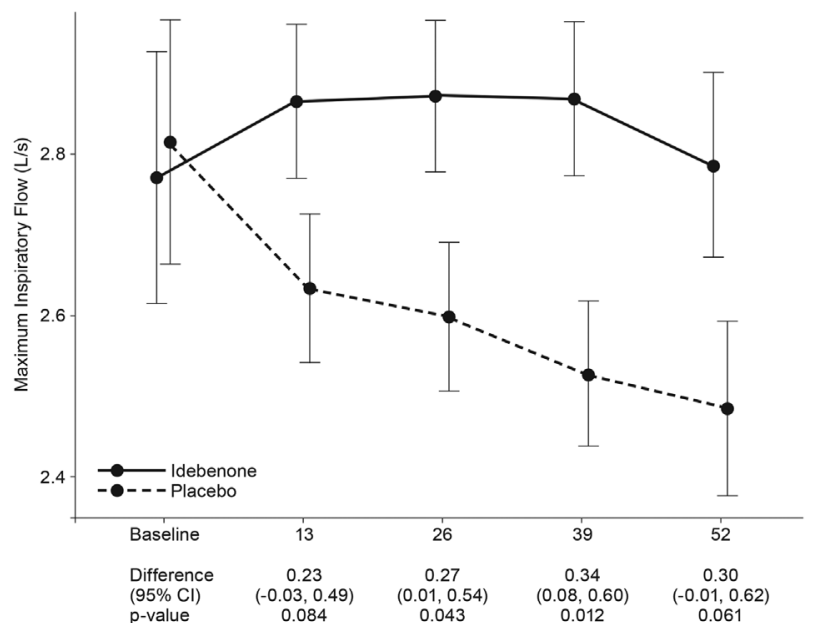

Fig. 2. Change of V'I,max(FVC) from baseline to week 52. Data are estimated means, standard errors (graph), and $95 \% \mathrm{Cl}$ from the mixed model for repeated measures for change from baseline to week $13,26,39$, and 52 .

\section{DISCUSSION}

This additional analysis of the DELOS trial indicates that inspiratory function is significantly impaired in 10-18-year-old DMD patients not taking GC and demonstrates that idebenone significantly reduces the loss of pulmonary function as assessed by inspiratory flow reserve. A non-significant trend $(P=0.061)$ favoring idebenone at week 52 was also observed on V'I, $\max (\mathrm{FVC})$. These findings corroborate previously reported data on the efficacy of idebenone in preserving expiratory muscle function in this patient population. ${ }^{17}$

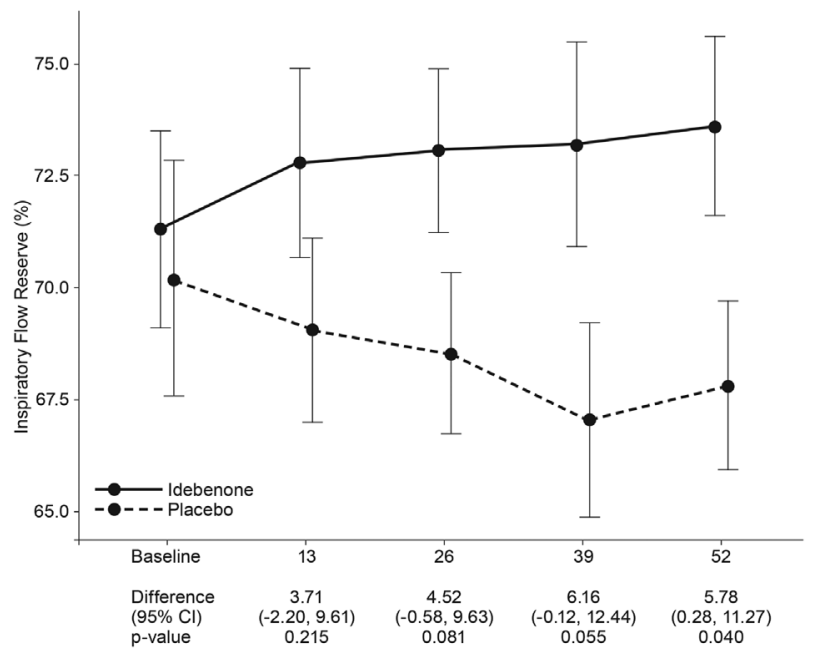

Fig. 3. Change of IFR (in \%) from baseline to week 52. Data are estimated means, standard errors (graph), and $95 \% \mathrm{Cl}$ from the mixed model for repeated measures for change from baseline to week 13, 26, 39, and 52 .

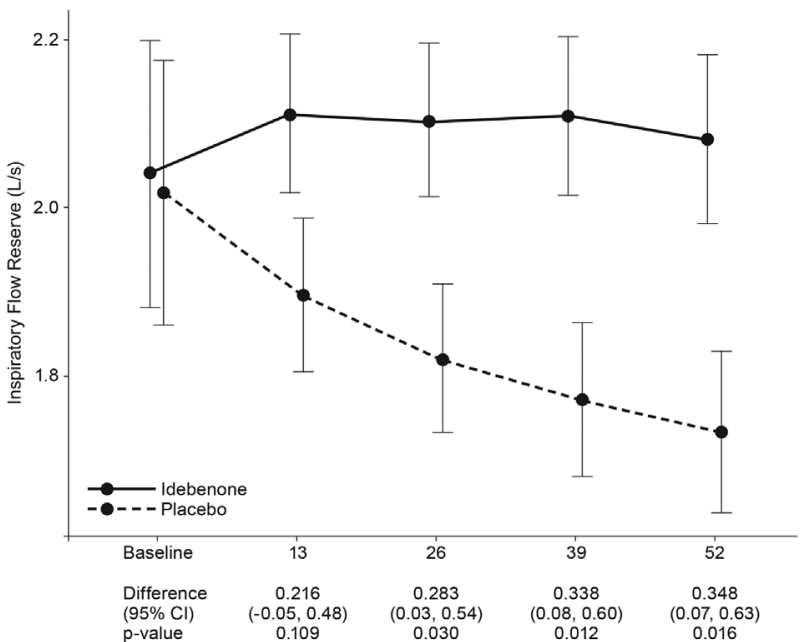

Fig. 4. Change of IFR (in L/sec) from baseline to week 52. Data are estimated means, standard errors (graph), and $95 \% \mathrm{Cl}$ from the mixed model for repeated measures for change from baseline to week $13,26,39$, and 52 .

Maximum inspiratory flow (e.g., the largest inspiratory flow generated during an inspiratory FVC maneuver, V'I,max (FVC)) provides an estimate of inspiratory muscle function in patients with DMD. ${ }^{16}$ In chronic neuromuscular diseases, decreases in $\mathrm{V}^{\prime} \mathrm{I}, \max (\mathrm{FVC})$ may be proportionately greater than maximum expiratory flow. ${ }^{29,30}$ This difference, which in DMD is augmented by the involvement of the diaphragm, is due to the effortdependence of V'I,max(FVC) and is amplified by an increase in lung recoil that offsets the effects of muscle weakness on expiration, but decreases the flow produced by a given (negative) pleural pressure on inspiration. ${ }^{31}$

De Bruin et al. ${ }^{16}$ have shown that maximum inspiratory flow is reduced in patients with DMD, and as a result of that the inspiratory flow ratio is increased and consequently the IFR reduced, both indicative of inspiratory function loss. The analysis we performed on the DELOS population generally confirms these findings. However, DMD patients in DELOS had higher V'I,max (FVC) at baseline (2.77 $\mathrm{L} / \mathrm{sec}$ in the idebenone group and $2.82 \mathrm{~L} / \mathrm{sec}$ in the placebo group) than those in the De Bruin study $(2.17 \mathrm{~L} / \mathrm{sec}) .{ }^{16}$ Similarly, FVC was also higher in DELOS $(1.88 \mathrm{~L}$ in the idebenone group and $1.86 \mathrm{~L}$ in the placebo group) than in the De Bruin study $(1.64 \mathrm{~L})$. Both differences could be explained by the older age (13.5 years and 15.0 years in the idebenone and placebo groups, respectively vs. 12.8 years) and the fact that patients were taller $(157 \mathrm{~cm}$ and $162 \mathrm{~cm}$ in the idebenone and placebo groups, respectively vs. $148 \mathrm{~cm})^{16}$ in DELOS. In addition, since the De Bruin study was published over 10 years ago, improved standards of care may also have accounted for a better preserved pulmonary function in patients with DMD enrolled in DELOS. Interestingly, both V'I,max(FVC) and IFR were not better in previous GC users compared to GC-näve 
patients, suggesting that the favorable long-term effect of GC use on pulmonary function had disappeared by the time patients enrolled in the study.

Our findings for V'I,max(FVC) and IFR point toward a protective role of idebenone on inspiratory muscle function such as the diaphragm, which is of clinical relevance. Indeed, contrary to earlier suggestions that the diaphragm might be selectively spared until a late phase of the disease, ${ }^{32}$ it has been demonstrated that diaphragm thickness is increased in patients with DMD below the age of 12 years due to connective tissue infiltration and fat deposition. ${ }^{33}$ Diaphragm pseudo-hypertrophy, which is similar to that observed in some limb muscle groups, is associated with significant reductions in spirometric measurements such as $\mathrm{FEV}_{1}, \mathrm{FVC}$, and PEF. ${ }^{33}$ Moreover, the diaphragm is in constant use and often displays the most severe pathology, as demonstrated in animal models of muscular dystrophy, leading to the conclusion that exercise may exacerbate degeneration. ${ }^{34}$

The clinical interpretation of the results reported here is limited by the fact that dynamic inspiratory function tests are currently not performed in the routine follow-up of DMD patients. Furthermore, as this is the second report on inspiratory function in DMD patients following the first description by De Bruin et al., ${ }^{16}$ there is currently a lack of reference data from natural history studies that would enable interpretation of the clinical relevance of the observed outcomes. Clearly, further work is needed to correlate changes in inspiratory functions tests to pulmonary function test outcomes commonly accepted to be of clinical relevance to DMD patients, such as decline in FVC or PEF. As available data are currently not sufficient to allow for such comparisons, measures of inspiratory function and changes observed are to be regarded as exploratory in nature and therefore robust clinical conclusions cannot be derived at this time. However, as inspiratory maneuvers assess the function of different muscle groups compared to those assessed during expiratory function tests (e.g., FVC, PEF), such data could still provide useful information.

In summary, idebenone reduced the loss of inspiratory pulmonary function as assessed by V'I,max(FVC) and IFR in patients with DMD. Stabilization of respiratory muscle function may potentially delay the emergence of respiratory failure in these patients. Although the clinical interpretation of these data is currently limited, these findings nevertheless expand on the previously reported effect of idebenone on expiratory muscle function in DMD patients and are of special interest as inspiratory and expiratory maneuvers rely on a different set of muscles. Studies of longer duration will be needed to further corroborate the encouraging treatment effects of idebenone on respiratory function outcomes as observed in the randomized controlled DELOS study. Of particular relevance will be the correlation between changes in pulmonary function outcomes and the clinical course over time. In this context, it is of particular interest that patients in the idebenone group of the DELOS study experienced fewer and shorter bronchopulmonary complications (such as airway infections) compared to patients in the placebo group, which is of clinical relevance. ${ }^{35}$

\section{ACKNOWLEDGMENTS}

The study was sponsored by Santhera Pharmaceuticals. The DELOS Study Group is indebted to the participating patients and their parents. The authors thank Marianne Mann, MD (Regulatory Consultant, Highland, MD) for suggestions on the analyses and Jonathan Finder, MD (University of Pittsburgh) for reviewing the manuscript.

\section{REFERENCES}

1. Bushby K, Finkel R, Birnkrant DJ, Case LE, Clemens PR, Cripe L, Kaul A, Kinnett K, McDonald C, Pandya S, et al. Diagnosis and management of Duchenne muscular dystrophy, part 1: diagnosis, and pharmacological and psychosocial management. Lancet Neurol 2010;9:77-93.

2. Eagle M, Baudouin SV, Chandler C, Giddings DR, Bullock R, Bushby K. Survival in Duchenne muscular dystrophy: improvements in life expectancy since 1967 and the impact of home nocturnal ventilation. Neuromuscul Disord 2002;12:926-929.

3. Goemans N, Buyse GM. Current treatment and management of dystrophinopathies. Curr Treat Options Neurol 2014;16:287.

4. Passamano L, Taglia A, Palladino A, Viggiano E, D’Ambrosio P, Scutifero M, Rosaria Cecio M, Torre V, Luca DEF, Picillo E, et al. Improvement of survival in Duchenne muscular dystrophy: retrospective analysis of 835 patients. Acta Myol 2012;31:121-125.

5. Rall S, Grimm T. Survival in Duchenne muscular dystrophy. Acta Myol 2012;31:117-120.

6. Melacini P, Vianello A, Villanova C, Fanin M, Miorin M, Angelini C, Dalla Volta S. Cardiac and respiratory involvement in advanced stage Duchenne muscular dystrophy. Neuromuscul Disord 1996;6:367-376.

7. Simonds AK. Respiratory complications of the muscular dystrophies. Semin Respir Crit Care Med 2002;23:231-238.

8. Bourke SC. Respiratory involvement in neuromuscular disease. Clin Med 2014;14:72-75.

9. Bushby K, Finkel R, Birnkrant DJ, Case LE, Clemens PR, Cripe L, Kaul A, Kinnett K, McDonald C, Pandya S, et al. Diagnosis and management of Duchenne muscular dystrophy, part 2: implementation of multidisciplinary care. Lancet Neurol 2010;9:177-189.

10. Birnkrant DJ, Bushby KM, Amin RS, Bach JR, Benditt JO, Eagle M, Finder JD, Kalra MS, Kissel JT, Koumbourlis AC, et al. The respiratory management of patients with Duchenne muscular dystrophy: a DMD care considerations working group specialty article. Pediatr Pulmonol 2010;45:739-748.

11. Smith PEM, Calverley PMA, Edwards RHT, Evans GA, Campbell EJM. Practical problems in the respiratory care of patients with muscular dystrophy. N Engl J Med 1987;316:1197-1205.

12. Tangsrud S, Petersen IL, Lødrup Carlsen KC, Carlsen KH. Lung function in children with Duchenne's muscular dystrophy. Respir Med 2001;95:898-903.

13. Pedersen OF. The Peak Flow Working Group: physiological determinants of peak expiratory flow. Eur Respir J Suppl 1997;24:11S-16S. 
14. Tzelepis GE, Zakynthinos S, Vassilakopoulos T, Geroulanos S, Roussos C. Inspiratory maneuver effects on peak expiratory flow. Role of lung elastic recoil and expiratory pressure. Am J Respir Crit Care Med 1997;156:1399-1404.

15. Hahn A, Bach JR, Delaubier A, Renardel-Irani A, Guillou C, Rideau Y. Clinical implications of maximal respiratory pressure determinations for individuals with Duchenne muscular dystrophy. Arch Phys Med Rehabil 1997;78:1-6.

16. De Bruin PF, Ueki J, Bush A, Manzur YA, Watson A, Pride NB. Inspiratory flow reserve in boys with Duchenne muscular dystrophy. Pediatr Pulmonol 2001;31:451-457.

17. Buyse GM, Voit T, Schara U, Straathof CS, D'Angelo MG, Bernert G, Cuisset JM, Finkel RS, Goemans N, McDonald CM, et al. Efficacy of idebenone on respiratory function in patients with Duchenne muscular dystrophy not using glucocorticoids (DELOS): a double-blind randomised placebo-controlled phase 3 trial. Lancet 2015;385:1748-1757.

18. American Thoracic Society/European Respiratory Society. ATS/ ERS statement on respiratory muscle testing. Am J Respir Crit Care Med 2002;166:518-624.

19. Quanjer PH, Stocks J, Polgar G, Wise M, Karlberg J, Borsboom G. Compilation of reference values for lung function measurements in children. Eur Respir J Suppl 1989;4:184S-261S.

20. Hankinson JL, Odencrantz JR, Fedan KB. Spirometric reference values from a sample of the general U.S. population. Am J Respir Crit Care Med 1999;159:179-187.

21. Domènech-Clar R, López-Andreu JA, Compte-Torrero L, De Diego-Damiá A, Macián-Gisbert V, Perpiñá-Tordera M, RoquésSerradilla JM. Maximal static respiratory pressures in children and adolescents. Pediatr Pulmonol 2003;35:126-132.

22. Gauld LM, Kappers J, Carlin JB, Robertson CF. Prediction of childhood pulmonary function using ulna length. Am J Respir Crit Care Med 2003;168:804-809.

23. Gauld LM, Kappers J, Carlin JB, Robertson CF. Height prediction from ulna length. Dev Med Child Neurol 2004;46:475-480.

24. SAS System for Windows version 9.3 (SAS Institute,Inc., Cary, North Carolina, USA).
25. R Core Team (2015). R: a language and environment for statistical computing. Foundation for Statistical Computing, Wien, Austria. http://www.R-project.org/

26. McDonald CM, Abresch RT, Carter GT, Fowler WM Jr., Johnson ER, Kilmer DD, Sigford BJ. Profiles of neuromuscular diseases. Duchenne muscular dystrophy. Am J Phys Med Rehabil 1995;74: S70-S92.

27. Abresch RT, McDonald CM, Henricson EK, Gustavo N, Hu F, Duong T, Joyce N, Mah J. P.11.11 pulmonary function characteristics of boys with Duchenne muscular dystrophy by age groups, ambulatory status and steroid use. Neuromuscul Disord 2013;23:801-802.

28. Abresch RT, McDonald CM, Henricson EK, Gustavo N, Hu F, Duong T, Joyce N, Mah J. P.11.12 Pulmonary function characteristics of boys with Duchenne muscular dystrophy: data from the CINRG longitudinal study project. Neuromuscul Disord 2013;23:802.

29. Gibson GJ, Pride NB, Newsom Davis J, Loh LC. Pulmonary mechanics in patients with respiratory muscle weakness. Am Rev Respir Dis 1977;115:389-395.

30. Vincken WG, Elleker MG, Cosio MG. Flow-volume loop changes reflecting respiratory muscle weakness in chronic neuromuscular disorders. Am J Med 1987;83:673-680.

31. De Troyer A, Estenne M. The respiratory system in neuromuscular disorders. In: Roussos C, editor. The thorax. New York: Marcel Dekker; 1995. pp 2177-2212.

32. Newsom-Davis J. The respiratory system in muscular dystrophy. Br Med Bull 1980;36:135-138.

33. De Bruin PF, Ueki J, Bush A, Khan Y, Watson A, Pride NB. Diaphragm thickness and inspiratory strength in patients with Duchenne muscular dystrophy. Thorax 1997;52:472-475.

34. Goldstein JA, McNally EM. Mechanisms of muscle weakness in muscular dystrophy. J Gen Physiol 2010;136:29-34.

35. McDonald CM, Meier T, Voit T, Schara U, Straathof CS, D'Angelo MG, Bernert G, Cuisset JM, Finkel RS, Goemans N, et al. Idebenone reduces respiratory complications in patients with Duchenne muscular dystrophy. Neuromuscul Disord 2016;26:473-480. 